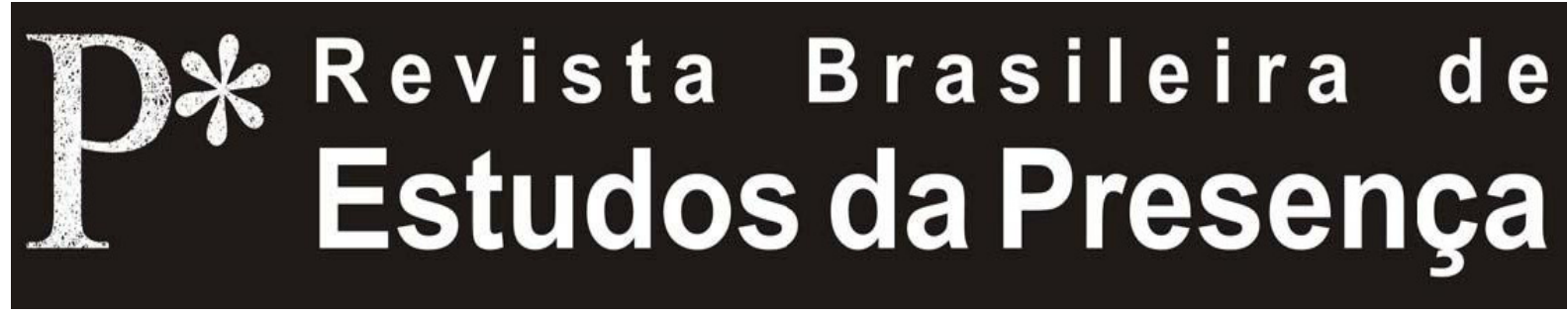

DOI - http://dx.doi.org/10.1590/2237-266039230

ISSN 2237-2660

\title{
Performatividad de Género y Travestismo a través de Escenificaciones de Las Criadas de Genet
}

\author{
Ezequiel Lozano \\ Universidad de Buenos Aires - UBA, Buenos Aires, Argentina
}

RESUMEN - Performatividad de Género y Travestismo a través de Escenificaciones de Las Criadas de Genet - Se reflexiona sobre los conceptos de travestismo y performatividad de género mediante la lente de los estudios queer, ejemplificando con sucesivas puestas en escena de Las Criadas de Jean Genet. Se trata de teatro producido por argentinos, en Buenos Aires y algunas otras ciudades del mundo, cuyo factor común reside no sólo en el texto dramático sino en los cuestionamientos a la idea de la representación. Los directores S. Renán, V. García, A. Arias y C. Zorzoli problematizan esta idea y nos permiten pensar la desestabilización operada por Las Criadas.

Palabras-clave: Travestismo. Performatividad. Género. Queer. Las Criadas.

ABSTRACT - Gender Performativity and Cross Dressing through some Stagings of Genet's The Maids - This article explores the concepts of cross dressing and gender performativity through the conceptualization of queer studies, exemplifying them with successive stagings of The Maids, by Jean Genet. It focuses specifically on Argentine directors, whose common feature lies not only in the dramatic text but in objections to the idea of representation, as Genet suggests in his text. S. Renán, V. García, A. Arias and C. Zorzoli problematise this idea, with each new staging, and allow us to reflect on the destabilization operated by The Maids.

Keywords: Cross Dressing. Performativity. Gender. Queer. The Maids.

RÉSUMÉ - Performativité du Genre et Travestissement dans les Mises en Scène de Les Bonnes de Genet - Lauteur se propose d'examiner les concepts de travestissement et de performativité du genre, au regard des études queer, en s'appuyant sur des mises en scène de Les Bonnes de Genet. Il s'agit de spectacles produits par des argentins, à Buenos Aires et dans d'autres ville du monde, dont le socle commun réside non seulement dans le texte dramatique mais aussi dans la remise en question de la représentation. Lanalyse des mises en scène de S. Renán, V. García, A. Arias et C. Zorzoli qui réfléchissent à cette idée, permettra de réfléchir sur la déstabilisation opérée par Les Bonnes.

Mots-clés: Travestissement. Performativité. Genre. Queer. Les Bonnes. 


\section{Introducción}

En el arte se evidencian variadas formas de travestismo en muchos géneros populares, plasmados en formatos de lo más diversos (cine, literatura, emisiones de radio etc.). Si bien es cierto que basta un mero panorama de la historia del teatro universal, en especial su praxis escénica previa a la presencia de las mujeres en los escenarios, para notar que este recurso no constituye una novedad en sí mismo, no deja de ser notorio que su utilización varía del mismo modo que los signos que construye. Por citar sólo un primer ejemplo, en los albores del sistema teatral argentino se puede reconocer un caso singular, aunque nada novedoso, de travestismo tematizado a través del juguete cómico La dama de compañia (1907) de Francisco E. Collazo, donde el cambio de identidad de género que atraviesa el personaje interpretado por el capocómico Florencio Parravicini no implica ningún tipo de cuestionamiento al sistema sexo-genérico hegemónico.

En los escenarios porteńos se pueden rastrear numerosos ejemplos de travestismo, y ello ocurre mucho antes de que las personas trans ingresen a los escenarios. Hablamos aquí de casos repetidos de actores y actrices que llevan el travestismo a la escena teatral. Como bien señalan Beatriz Trastoy y Perla Zayas de Lima, se puede visualizar una diferencia clara entre un empleo estetizante de este recurso escénico, un uso cuestionador y otro paródico. En el primer caso, al ocultar o disimular sutilmente las marcas sexuales diferenciadoras, no se busca provocar hilaridad entre el público, sino, muy por el contrario, despertar admiración frente al virtuosismo interpretativo (2006, p. 99). Diferente es la semántica que maneja la opción del travestismo cuestionador que resulta provocativamente ambiguo; en éste, los detalles más insignificantes de todo el aspecto físico de la o el intérprete se ven reforzados por las marcas de género del discurso verbal y gestual construyendo una imagen de femineidad o masculinidad quebrada abruptamente cuando se deja ver algún rasgo físico particular y real que difiere de ese imaginario. Es este travestismo el que cuestiona el binarismo de género dominante (2006, p. 100); por ello, es el que más interés nos despierta desde una perspectiva queer. En tercer lugar, el travestismo permite en otros casos construir una forma particular de parodia a los roles sociales y a ciertos estereotipos de mujeres y hombres pertenecientes a sectores sociales específicos. 
El semantismo de la figura travestida, en su mayoría hombres devenidos mujeres a través de cuidadosas estrategias de vestuario, maquillaje, gestualidad y voz, traza un amplio arco que va de la exaltación admirativa a la burda caricatura de lo femenino (Trastoy; Zayas de Lima, 2006, p. 98).

Apoyados en los estudios queer, enaltecemos la potencialidad política del travestismo cuestionador, puesto que intenta convertirse en un signo teatral desestabilizador del binarismo de género heteronormado que a tantas personas encasilla de modo compulsivo, sin habilitar puntos de fuga ni comprender las diferencias. Se trata de un proceso para desnaturalizar la programación de género, esa tecnología de modelización de la subjetividad de individuos que se autocomprenden con una identidad genérica y una sexualidad fijas. Esta herramienta escénica forma parte de un conjunto de operaciones de desnaturalización y desidentificación.

Ahora bien, ¿¿de qué se trata esta programación? Como explica la filósofa Beatriz Preciado, "la programación de género dominante parte de la siguiente premisa: un individuo $=$ un cuerpo $=$ un sexo $=$ un género = una sexualidad" (Preciado, 2008, p. 90-91). Al afirmar eso, ella se basa en una consideración anterior que vale la pena recordar: el género es performativo. Judith Butler argumentó certeramente que esto es así; El género en disputa se titula el libro que delimita claramente la idea. Allí se afirma que eso que se naturaliza como algo dado es una construcción extendida en el tiempo mediante un conjunto sostenido de actos que apuntan a la estilización del cuerpo. De modo que, observando este fenómeno en nuestra propia experiencia personal, podemos descubrir que aquello que llamamos esencia interna del género en nosotros/as mismos/as "[...] es algo que anticipamos y producimos a través de ciertos actos corporales [...] un efecto alucinatorio de gestos naturalizados" (Butler, 2007, p. 17). Esto sucede en el interior de un sistema binario cuyas normas son obligatorias e interpelan a las personas a definirse como masculinas o femeninas; dicha obligatoriedad indica que "[...] la reproducción del género es siempre una negociación de poder" (Butler, 2009, p. 322). El modo en el que aparecemos en el espacio público y de qué manera lo hacemos se vincula estrechamente con esas normas de género. Se trata de una reglamentación que determina,

[...] cómo y de qué manera se distinguen lo público de lo privado y cómo esta distinción se instrumentaliza al servicio de las políticas sexuales; quién estará criminalizado según la apariencia pública; quién no será protegido por la

Ezequiel Lozano - Performatividad de Género y Travestismo a 
ley o, de manera específica, por la policía, en la calle, o en el trabajo o en casa (Butler, 2009, p. 323).

O sea que, en términos de Preciado (2008), desmontar la programación de género conforma un proceso de deconstrucción que podría asemejarse a lo que Judith Butler denomina deshacer el género. Así, el cuestionamiento que el jeroglífico teatral del travestismo habilita, en algunos casos, opera como desmontaje de esa programación.

El presente artículo intentará, entonces, analizar algunas experiencias escénicas que, deconstruyendo la idea de representación, habilitan a ser leídas desde la óptica de los dos conceptos explicados hasta aquí: travestismo y performatividad de género.

\section{Apuntes Introductorios a Las Criadas de Jean Genet}

Desde el momento de su escritura, en 1947, se reflexiona casi ininterrumpidamente sobre Las criadas: ejemplo emblemático es el ensayo apologético de Sartre sobre su autor, Jean Genet (1910-1986). Ya el texto dramático es un discurso en torno a otro que lo antecede: el relato de un caso real de asesinato cometido por las hermanas Papin que conmocionó a Francia, allá por 1933. Y no sólo el texto dramático en cuestión deja huella de esa conmoción en la intelectualidad francesa, sino que varios pensadores, como Lacan o Simone de Beauvoir, reflexionan contemporáneamente sobre el caso. Aún así, vale recordar que el texto de Genet parte de esa imagen para crear un mundo absolutamente autónomo del relato del crimen real de la señora empleadora y de su hija. Y es en ese armado ficcional, en esa trama lúdica ideada por el autor de Diario del ladrón, sobre la cual se disparan las puestas en escena de las cuales intentaremos reflexionar aquí.

Dada la vasta producción analítica que el texto dramático desplegó nos interesa centrarnos exclusivamente en algunos aspectos específicos del mismo que nos permitan analizar algunas escenificaciones del mismo vinculadas con Argentina a través de sus hacedores. Vale aclarar que, si bien tomamos puestas en escena de diferentes momentos históricos, no es el propósito de este escrito historizar todas las producciones argentinas basadas en Las Criadas de Genet.

\section{De Artificios y Accesorios}

Solange, Claire y la Señora, los tres personajes creados por Genet, son oficiantes de un rito en varios planos. Por una parte las dos 
criadas tienen un objeto de culto, la Señora, quien por esto, al decir de Marta Segarra, "resulta aún más descarnada" (2011, p. 95). En la puesta en escena parisina, de 2001, del argentino Alfredo Arias, se señala este aspecto descarnado y de ideal femenino artificialmente construido para la mirada ajena. ¿De qué manera? El propio director interpreta el rol de la Señora travestido, pero de modo claramente artificioso, remitiendo a una muñeca antes que a una mujer. Vestuario que denuncia un carácter mecánico no exento de capacidad para convertirse en objeto de adoración en el juego ceremonial. Las dos hermanas criadas (interpretadas por Marilú Marini y Laure Duthilleul) adoran a la Señora. La deconstrucción de la identidad genérica que habilita el signo teatral del cuerpo travestido de Arias en su puesta en escena de ningún modo es unívoco, sino que estalla en posibilidades interpretativas. Una de éstas, como venimos diciendo, es el seńalamiento de "la femineidad" como algo construido y artificial, como una máscara hiperbólicamente adornada con atributos asignados, desde la cultura, a los rasgos femeninos (vestidos, maquillaje, joyas etc.) (Segarra, 2011, p. 96). La puesta de Arias se pudo ver en Buenos Aires al año siguiente de su estreno en Francia y, sobre este aspecto, una crítica señalaba la artificiosidad extrema desde la cual el director e intérprete construye y deconstruye a su personaje. "Va despojando a esa mujer de su rostro, de su pecho, de sus caderas - todos apósitos de plástico - para mostrar una masa amorfa sin identidad ni sentimientos" (Freire, 2002, s/p). La performatividad de género queda expuesta a la mirada del público.

Ahora bien, el travestismo de la puesta de Arias no conforma un hito de la dirección escénica de Las criadas puesto que una sugerencia del propio Genet (quien años después se desdijo) pretendía que esta obra, de tres personajes femeninos, sólo fuera interpretada por hombres. En Argentina, las versiones de 1959 y 1967 no escuchan esta propuesta inicial del francés; quien sí lo hace es Sergio Renán que en 1970 pone en escena la obra en el teatro SHA de Buenos Aires. La Nación, en su crítica a la puesta de Renán aclara que

[...] es ésta la primera vez que, según el deseo del autor, se la representa con hombres en los tres únicos papeles femeninos. Sartre no cree que esta indicación sea un capricho de Genet. Hace notar que en esta sucesión de apariencias la primera vuelta de tuerca es precisamente esta propuesta de identidades falsas; los intérpretes son ostensiblemente falsas mujeres y en los personajes que van asumiendo son, a su vez, falsos hombres. Aquí hay algo más que una con- 
vención. Al margen del ser ambiguo y genérico (quedan sólo categorías, como la servil y la señoril) que Genet quiso simbolizar, 'Las criadas' propone en varios niveles una búsqueda desesperada de la identidad (s/f, 1970, p. 3).

El crítico remarca esta idea de falsedad, que podríamos criticar bastante desde el contexto actual, pero señala un aspecto central de la puesta como una desesperada búsqueda identitaria.

A diferencia de este crítico, el conservador Jaime Potenze opina, en La Prensa, que la interpretación masculina de los personajes de Solange, Claire y la Seńora constituye

[...] un error porque los caracteres son femeninos hasta la médula: les gusta el lujo, adoran la ropa elegante, no son indiferentes a los perfumes. Al darle una tónica masculina (porque no hay aquí indefinición sino travestis), la pieza se resiente de inverosimilitud, lo que podrá no importar a Genet, pero sí al espectador, que aunque acepte las reglas del juego, aspira a que haya en ellas cierta coherencia (Potenze, $1970, \mathrm{~s} / \mathrm{p})$.

Son curiosos los caracteres que para el crítico definen la médula de lo femenino: el gusto por el lujo, la elegancia en el vestir y su interés por oler bien, todos accesorios. Porque el sustrato de esta argumentación es que el género es un accesorio, de modo que lo que define la masculinidad o la femineidad es un anexo al cuerpo que conforma una imagen. Será desde esta lógica que, pocos años después, Copi lo plasme poéticamente en La Torre de la Defensa (1977), poniendo en boca de dos de sus personajes:

Micheline: ¿Me preferís como hombre o como mujer?

Ahmed: Con los anteojos, como hombre; con la peluca, como mujer [...] (Copi, 2011, p. 127-128).

Claro que Potenze no está pensando en lo que sus palabras habilitan, porque evidencia las huellas del paradigma dominante que liga necesariamente sexo y género, donde a un sexo le corresponde un y sólo un género particular de modo obligatorio y compulsivo. Para él, los accesorios se usan de acuerdo a la naturaleza. En cambio, para Copi, teatrista muy cercano al pensamiento de la teoría queer antes de que la misma existiera, lo que denominamos naturaleza es una construcción.

El artículo de Clarín (s/f, 1970, s/p) destaca la solidez de los trabajos actorales de Walter Vidarte y Luis Brandoni. En general, las críticas son más modestas para referirse al trabajo de Héctor Alterio en el rol de la Señora. Por su parte, Kive Staiff, en su nota de 
la revista Análisis, caracteriza la marginalidad de Genet y lo describe como un "hombre de sexualidad y moralidad dudosas" (Staiff, 1970, $\mathrm{s} / \mathrm{p}$ ). Entiende que la sugerencia del autor para que sus personajes de Las criadas lo interpreten hombres es un recurso para indagar sobre el bajo fondo de la naturaleza humana esfumando las diferencias entre los sexos.

[...] ficciones acaso más satisfactorias que la realidad objetiva porque corresponden a una realidad más verdadera y porque los papeles se intercambian (criadas, señoras, hombres, mujeres) hasta desaparecer como tales, hasta adquirir una pureza ominosa pero esencial (Staiff, 1970, s/p).

Por esto puede elogiar la tarea actoral valorando positivamente su coraje para "ser mujeres sin dejar de ser hombres y, por esta vía, trasmutarse en puro símbolo" (Staiff, 1970, s/p).

A diferencia de esta posición más abierta de Staiff, el crítico Victor Max Wullich entiende el travestismo sugerido por Genet es motivado por el deseo de alejar la obra del caso real de las hermanas Papin ${ }^{1}$. Coincide con Staiff cuando comienza su artículo en Confirmado haciendo una semblanza biográfica de Genet para remarcar su notoria homosexualidad y su vida de delincuencia. Pero valora muy positivamente el resultado del recurso del travestismo. Entiende que Renán logra demostrar que

[...] aquella concepción original de Genet no era tan descabellada. El endemoniado intríngulis, al asexuarse (porque ese es el efecto), tórnase en la lucha imprecisa entre el Bien y el Mal (Wullich, 1970, s/p).

Según explica, eso sucede gracias a que el director reduce al justo límite la idea original con intérpretes que demuestran sobriedad y empeño en "no convertir en una guarangada la idea de los travestis, que funciona limpiamente sin un solo golpe bajo" (Wullich, 1970, $\mathrm{s} / \mathrm{p})$. Por cierto, esta última idea que subraya Wullich se arrastra en el imaginario de la crítica argentina desde sus orígenes: entender el travestismo como un borde entre la sobriedad y la ofensa (guarangada, lo llama aquí). De algún modo se considera, así, que si el cuestionamiento genérico efectuado por el jeroglífico escénico del travestismo es muy fuerte; su calidad estética es menor y de baja factura. Claramente, se trata de una idea transfóbica que se repite en reiteradas oportunidades desde inicios del sistema teatral argentino hasta fines del siglo XX, por lo menos. 
Pero también es cierto que Wullich aporta un dato relevante: habla de la puesta de Víctor García, que él mismo vio en París. Dice que el tucumano "supo entregar toda la violencia, toda la amargura, todo el sarcasmo, todo el odio y toda la poesía, también, que rezuma el texto" (Wullich, 1970, s/p). Se trata de otro director argentino, que emigra del país en la década del sesenta y obtiene un reconocimiento internacional único por sus trabajos en diferentes países de Europa y en Brasil. Sobre su vasta y compleja concepción del teatro no podemos detenernos en este escrito, por lo cual remitimos al notable estudio que le dedicó Juan Carlos Malcún (2011), donde se observa, de modo ejemplar, lo fundamental que resulta el espacio escénico en sus puestas en escena.

Esta concepción de Las Criadas se estrena en 1969, primero en el Poliorama de Barcelona y, ese mismo ańo, en la Ciudad Universitaria de París. Años más tarde, en 1984, se pudo ver en Buenos Aires, en una reposición española. Sobre el dispositivo escénico, diseñado por Víctor García, Juan Carlos Malcún (2011) describe que se trataba de una cámara de espejos, construida con paneles suspendidos de aluminio (1,20 m de ancho x $9 \mathrm{~m}$ de alto) que, sin tocar el suelo, dibujaban un zócalo de aire de color negro. Ese anillo negro enmarcaba la celebración ritual ${ }^{2}$. Los paneles, independientes entre sí, rodeaban perimetralmente el espacio escénico y conformaban, igualmente, un muro vertical sólido, continuo y curvo, que reflejaba lo que sucedía en su centro.

Poseía ejes de una rigurosa simetría especular, que atravesaban la sala y el espacio escénico, en el sentido longitudinal. Un escenario de fuerte pendiente lograba, paradójicamente, un equilibrio inestable, que producía tensión-calma-tensión; e invadía y movilizaba, en todo momento, la atmósfera de la representación (Malcún, 2011, p. 139).

El espacio invocaba más bien aquella interpretación sartreana del texto del otro como espejo identitario, el juego entre la imagen real y la imagen reflejada se concretaba antes en el dispositivo escénico que en las intérpretes mujeres. Éstas, a su vez, portan en sus pies unos coturnos que las alejan del mundo cotidiano para reingresarlas, como actrices (y no actores travestidos), al arcaico mundo ritual de la tragedia griega (donde, recordemos, no había mujeres intérpretes, sino actores que, travestidos, llevaban adelante los roles femeninos). Lo interesante es pensarlo desde el lugar de la iteración que tienen tanto el rito como la performatividad de género: una serie de pasos 
que se repiten cada vez. A la par de pensar el subrayado que ya hace el texto de Genet y que la puesta de García hiperboliza: el cruce de la categoría de género con la de clase, la performatividad está entrecruzada por ambas.

\section{Presentación/Representación}

La reciente puesta en escena de Ciro Zorzoli (2012), que también interpretan tres mujeres, remarca, igualmente, a través de los accesorios del vestuario de la Señora, la construcción de una imagen social del género cruzado con el concepto de clase. En este caso son fundamentalmente las pelucas que dan cuenta de la teatralidad social que sostiene el poder del ama sobre las esclavas, tanto como una femineidad superior a la de quienes sólo dedican su vida a servir.

Pero, antes de ahondar en la propuesta de Zorzoli, volvamos, brevemente, al primer ejemplo seńalado. La singularidad del director e intérprete Alfredo Arias, reverenciado en escena como Señora por sus dos actrices dirigidas, las criadas, que son personajes que, a su vez, representan (así comienza la obra), nos permite reflexionar sobre la figura de la dirección teatral y su vínculo con los y las intérpretes. No es novedad que al siglo pasado se lo calificó de la tiranía del director. De algún modo, la reverencia, la adoración a la par del odio profundo y el deseo de muerte proyectado en su figura concretan, en el significante de la Señora, esa vastedad discursiva. Porque ya el texto dramático construye, de modo patente, una reflexión honda sobre el problema de la representación. Y es en la escenificación de este punto clave donde los diversos directores de escena evidencian el núcleo de su propuesta estética. Las criadas ofician un rito para ellas mismas, así como para la Señora; las tres, al mismo tiempo ofician la ritualidad propia de la escena teatral sobre un escenario; y ellas, junto al público y los demás integrantes del equipo técnico y artístico, ofician, noche a noche, la representación de Las criadas de Jean Genet. Por eso, el abordaje que cada puesta haga sobre el tópico de la representación será necesariamente metateatral; el hacer de cada director/a dará cuenta de una reflexividad y una mirada del propio oficio ceremonial del teatro.

La puesta de Zorzoli es magnífica en este aspecto. Parte de algo previo sumamente rico: el director viene haciendo una profunda investigación escénica sobre el problema de la representación, tanto en su trabajo docente como en sus espectáculos previos. El niño en 
cuestión (2005), Estado de Ira (2010) y Exhibición y desfile (2010) son tres ejemplos contundentes en este sentido. En ellos pudo problematizar en escena, mediante una poética propia, la actuación y la mirada que la sostiene, del mismo modo que puso en evidencia los mecanismos de construcción de teatralidad. En esa línea, la coherencia con la que esta búsqueda se presenta en su labor sobre el texto dramático de Genet no podría ser mayor. Para ello, la conjunción con la escenografía de Oria Puppo es central: como una especie de altar, en el centro del escenario, la habitación de la Señora queda sola en un marco de desierto, teatralmente construido. Esta denuncia del artificio escenográfico, donde abrir una ventana practicable puede transformarse literalmente en quitarla de la pared, pretende sumar elementos a su pensamiento sobre la representación. El elemento más novedoso en este sentido es el agregado de un personaje en su puesta, llamado Omar, que opera como asistente de escena de las actrices. Está en el escenario todo el tiempo siguiendo el texto que se representa y quitando o agregando trastos de escenografía y utilería (asistido, a la vez por los utileros reales de la sala). Las actrices gritan su nombre para llamarlo y él debe responder. La tiranía se muestra en el aquí y ahora de la representación y reproduce la dominación clasista al interior del quehacer teatral. Lo más curioso es que, como en los demás trabajos dirigidos por Zorzoli, si bien el mecanismo repetitivo es sumamente preciso, siempre habilita zonas de improvisación dentro de los mecanismos lúdicos que sostienen el juego arriba del escenario. En este caso, el juego de Omar en escena permitió que en una de las funciones a la que asistimos, por ejemplo, sonara el teléfono celular de un espectador en la platea y que ello motivara a que una de las actrices le gritara, al asistente, ;Omar! ;El ruido! logrando que éste se acercara a la platea para dirigirse al público para apercibirlo diciendo: por favor, el ruido.

En la puesta de Zorzoli, no se trabaja con el travestismo para subrayar la representación. Marilú Marini, la actriz argentina que en la versión de Arias interpretaba a una de las criadas, es en esta puesta en escena la Señora. El mayor signo de reflexividad sobre el aspecto representacional lo dan las enérgicas actuaciones de las tres intérpretes, y, en ese aspecto la de Marini es ejemplar, ya que, a través del uso de diversas pelucas, logra que su cuerpo y su voz actúen su género y su clase, del mismo que su ausencia la desenmascaran. 


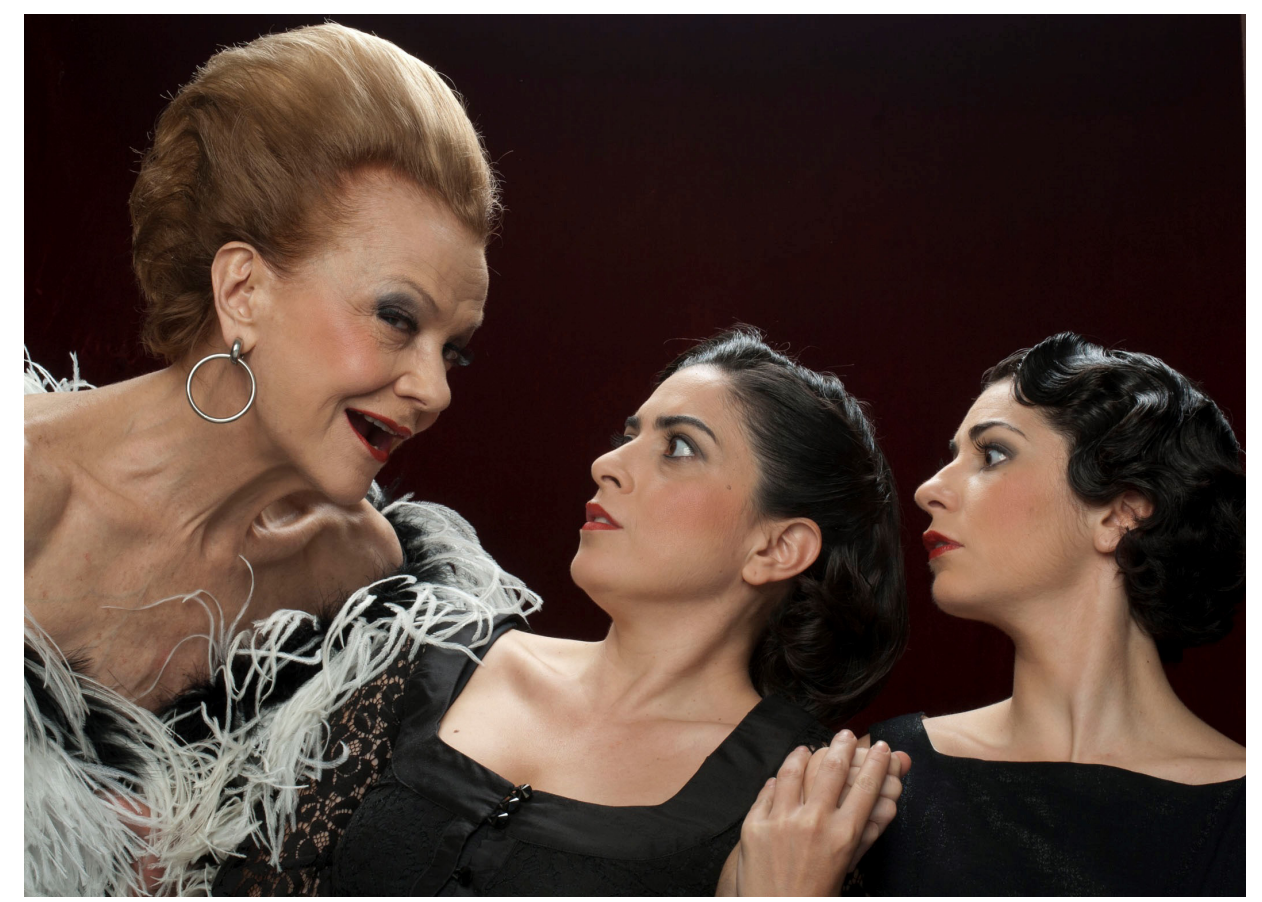

Imagen 1 - Marilú Marini, Paola Barrientos y Victoria Almeida. Las criadas (2012). Dirección de Ciro Zorzoli, Teatro Presidente Alvear, Buenos Aires, Argentina. Fotografía de Carlos Furmann, gentileza del Departamento de Prensa del Complejo Teatral de Buenos Aires.

\section{Lo trans de Las Criadas}

Lo cíclico de todo rito, su insistencia en instalar un tiempo otro mediante etapas en su realización permite visualizar las fallas, las omisiones de cada reiteración. La obra comienza con Claire y Solange en su reiterada escenificación de las maneras de vincularse con su empleadora representando la primera a la señora y la segunda a su hermana. En el juego utilizan los objetos de la habitación de la señora con pavor, por su miedo a dejar huellas de esa representación para cuando la verdadera seńora regrese. La falla sucede y es por esto que las criadas pueden pensar que los objetos las están abandonando y traicionando. Explica Segarra esta operación del texto de Genet afirmando que

[...] la elección de este verbo tampoco es gratuita: 'traicionar' proviene del latín transdo, que significa 'entregar' y contiene el prefijo 'trans' ('del otro lado', 'más allá'). Los objetos están dotados, pues de una movilidad, de una autonomía que los convierte casi en seres vivos, o al menos les otorga voluntad propia. No obstante, entre los objetos que actúan según su propia voluntad, las criadas incluyen también partes de su propio cuerpo, como las manos o los labios (Segarra, 2011, p. 100). 
¿Se puede representar sin dejar huellas? Somos performers, inconscientes o no, de nuestro género, ¿el travestismo escénico no es otra cosa que la radiografía de esa performatividad? En resumen, las puestas en escena de Víctor García (1969), Sergio Renán (1970), Alfredo Arias (2001) y Ciro Zorzoli (2012) asumen estas preguntas y les otorgan respuestas muy disímiles, pero no dejan de problematizar la cuestión de la performatividad de género, tan central en la teoría queer.

Del otro lado de la representación el teatro presenta la crisis de la representatividad como tal. De formas más o menos diáfanas todas las puestas aquí analizadas dan cuenta de esos cuestionamientos porque ya Genet los habilitaba con su escritura. Las criadas, al remarcar el carácter artificial de estos constructos escénicos, habilita el visionado de aquellos aspectos de la performatividad escénica que desmantelan la teatralidad social hegemónica en tanto agencias micropoliticas. 


\section{Notas}

${ }^{1}$ Informa: "Jouvet, que estrenó la obra en 1947, fue autorizado a no respetar la indicación, y la misma pareció caer en desuso, porque el tremendo texto conoció versiones que lo convertían poco menos que en algo boulevardier" (Wullich, 1970, s/p).

2 "En la cámara espejada, [...], se privilegiaba el lugar del ritual y, a la vez, era cama de la habitación de la "señora". Enmarcada con un fondo de acceso a la habitación, el lugar más alto del escenario, captaba la mirada del espectador hacia las puertas de acceso, focalizado con grandilocuentes efectos de luz y sombras que hablaban de un más allá, distinto al de una simple puerta de entrada. Nos imponía, metafóricamente, la presencia de un espacio de misterio en el lado no visible de la escena (extra-escena), atrás de la cortina metálica" (Malcún, 2011, p. 139-140).

\section{Referencias}

BUTLER, Judith. El Género en Disputa. El feminismo y la subversión de la identidad. Barcelona: Paidós Ibérica, 2007.

BUTLER, Judith. Performatividad, precariedad y políticas sexuales. AIBR - Revista de Antropología Iberoamericana, Madrid, v. 4, n. 3, p. 321-336, sep./dic. 2009.

COPI. Teatro I. Buenos Aires: El Cuenco de Plata, 2011.

FREIRE, Susana. Herencia de una Tradición de Rebeldía. La Nación, Buenos Aires, 14 sep. 2002. Disponible en: <http://www.lanacion.com.ar/431388-herencia-de-una-tradicionde-rebeldia>. Acceso en: 18 mar. 2013.

LLOYD, Moya. Performativity, Parody, Politics. Theory, Culture \& Society, Nottingham, v. 16, n. 2, p. 195-213, abr. 1999.

MALCÚN, Juan Carlos. Los Muros y las Puertas en el Teatro de Víctor García. Buenos Aires: INTEATRO, 2011.

POTENZE, Jaime. Digna Versión de una Obra Sobrevalorada. La Prensa, Buenos Aires, s/p, 10 jul. 1970.

PRECIADO, Beatriz. Testo Yonqui. Madrid: Espasa Calpe, 2008.

S/F. Las Criadas: Trascendente Obra que Revela el Talento Directivo de Renán. Clarín, Buenos Aires, s/p, 12 jul. 1970.

S/F. Un Juego Sutil y Amargo con los Sirvientes en una Obra de Genet. La Razón, Buenos Aires, s/p, 14 jul. 1970.

S/F. Decorosa Versión de una Difícil Obra de Jean Genet. La Nación, Buenos Aires, p. 3, 10 jul. 1970.

SEGARRA, Marta. Deseo y Violencia: Las criadas de Jean Genet. In: ANDRÉS, Rodrigo. Homoerotismos Literarios. Barcelona: Icaria, 2011. P. 91-108.

STAIFF, Kive. La Vuelta del Ritual. Análisis, Buenos Aires, s/p, 21 jul. 1970. 
TRASTOY, Beatriz; ZAYAS DE LIMA, Perla. Lenguajes Escénicos. Buenos Aires: Prometeo, 2006.

WULLICH, Víctor Max. Un Vigente Genet y un Miller algo Caduco. Confirmado, Buenos Aires, s/p, 15 jul. 1970.

Ezequiel Lozano es licenciado en Artes y doctorando en la Facultad de Filosofía y Letras de la Universidad de Buenos Aires (UBA - Argentina). Es becario del Consejo Nacional de Investigaciones Científicas y Técnicas - CONICET. Investigador teatral, colaborador permanente de Asociación Argentina de Investigación y Crítica Teatral - AINCRIT y docente universitario. Además, es actor, y director teatral. Durante 2013 continúa su trabajo actoral en la obra La Patria fría de Andrés Binetti y Mariano Saba.

E-mail: lozanoezequiel@gmail.com

Recibido el 23 de abril de 2013 Aceptado para publicación el 03 de julio de 2013 